\title{
Conformational Analysis of Toxogonine, TMB-4 and HI-6 using PM6 and RM1 Methods
}

\author{
Arlan da Silva Gonçalves, ${ }^{a}$ Tanos C. C. França, ${ }^{b}$ \\ José D. Figueroa-Villar ${ }^{b}$ and Pedro G. Pascutti*,a \\ anstituto de Biofísica Carlos Chagas Filho, Universidade Federal do Rio de Janeiro, \\ 21941-902 Rio de Janeiro-RJ, Brazil
}

${ }^{b}$ Divisão de Ensino e Pesquisa, Seção de Engenharia Química, Instituto Militar de Engenharia, 22290-270 Rio de Janeiro-RJ, Brazil

\begin{abstract}
Neste trabalho, após validação por comparação com resultados obtidos por DFT, os métodos semi-empíricos PM6 e RM1 foram utilizados para análise conformacional de três oximas usadas em defesa química. Os resultados sugerem conformações de menor energia destes compostos que poderão ser utilizadas em futuras parametrizações para estudos por modelagem molecular.

In this work, after validation by comparison with results obtained by DFT, the semi-empirical methods RM1 and PM6 were employed to perform conformational analysis of three oximes employed in chemical defense. The results suggested low energy conformations for those compounds that could be useful in further parameterizations for molecular modeling studies.
\end{abstract}

Keywords: acetylcholinesterase, conformational analysis, oximes, neurotoxic agents

\section{Introduction}

The intensive use of neurotoxic organophosphorous compounds (OPCs) as pesticides in agriculture, as well as their potential use as chemical warfare agents, has attracted the attention of the scientific community to develop efficient antidotes for this class of poisons.

One particularly important family of chemicals used in tactical warfare is the group broadly defined as nerve agents. They are closely related in chemical structure and biological action to many commonly used organophosphorous insecticides, but they are much more lethal.

Nerve agents are esters of phosphoric acid that act as potent inhibitors of acetylcholinesterase (AChE), a fundamental enzyme for terminating neurotransmissions in all living animals. These compounds inhibit all AChEs, including the human enzyme (HuAChE), by phosphylating a serine hydroxyl group (Ser203 in HuAChE), which is directly responsible for the hydrolysis of the neurotransmitter acetylcholine. This reaction occurs very rapidly and can lead to irreversible inhibition by a process called aging. ${ }^{1}$ Before aging, the inhibition of $\mathrm{AChE}$

\footnotetext{
*e-mail: pascutti@biof.ufrj.br
}

can be reversed through dephosphylation of the serine residue by a nucleophile, usually an oxime (Figure 1).

Despite the existence of many different oximes in use today as antidotes against intoxication by neurotoxic agents, the literature has yet to report a universal oxime that is able to act efficiently against all existing neurotoxic agents. What has been observed experimentally is that oximes efficient in the treatment of intoxication by one specific nerve agent can be completely ineffective against another. ${ }^{2-5}$ This probably happens because the mechanism of these compounds inside the AChE active site has not been fully elucidated yet. Some relevant factors required for obtaining a better understanding of this mechanism, like the orientation of the phosphoryl bond inside the active site, the proper charge and conformation of the oxime and the optimal angle for attacking the phosphylated serine, remain unknown. ${ }^{6}$ Theoretical studies have shown, for example, that the appropriate conformation is a fundamental requirement for the oxime to enter into the AChE active site's gorge, ${ }^{6-10}$ reinforcing the importance of conformational analysis studies of these compounds.

Several models of the mechanism and differences in activities among oximes have been proposed in the literature. ${ }^{6-12}$ A docking energy calculation by Castro et al. ${ }^{11}$ showed that 
pralidoxime (2-PAM), one of the oximes most commonly used as an antidote against neurotoxic agents, in its lowest energy conformation, E-anti-anti, remained in a possible reactivation region in the $\mathrm{AChE}$ active site. This observation was confirmed by molecular dynamics simulations, where the E-anti-anti conformation and the positive charge of 2-PAM $(+1)$ were shown to be fundamental for its permanence inside HuAChE's active site. ${ }^{12}$

In the present work, we performed conformational analysis studies using semi-empirical methods for the determination of possible global and local minima in each of the three different oximes: Toxogonine, ${ }^{13} \mathrm{TMB}-4^{14,15}$ and HI- $6 .{ }^{16}$ The results obtained will be useful in parameterizing these molecules for further molecular modeling studies of their potential as AChE reactivators.

\section{Methodology}

The structures of Toxogonine, TMB-4 and HI- 6 were built manually with GHEMICAL $2.10^{17}$ using the TRIPOS 5.2 force field. ${ }^{18}$ Classical optimizations were carried out followed by a random conformational search using GHEMICAL $2.10,{ }^{17}$ in order to find structures near possible global minima. Then, the semi-empirical methods $\mathrm{RM}^{19}$ and PM6 ${ }^{20}$ implemented in MOPAC $2007^{20}$ were used in two principal dihedral angles in those molecules, denoted $\Phi_{1}$ and $\Phi_{2}$ in Figure 2, which could causes further steric effects between two or more groups (i.e., aromatic rings) after optimizing the other degrees of freedom in the molecules.

The validations of RM1 and PM6 for conformational analysis were performed by calculations using the GAUSSIAN 2003 software package. ${ }^{21}$

Both dihedral angles, $\Phi_{1}$ and $\Phi_{2}$, were scanned from 0 to 360 degrees in 5-degree steps. This was performed with the MOPAC $2007^{20}$ software package using the following

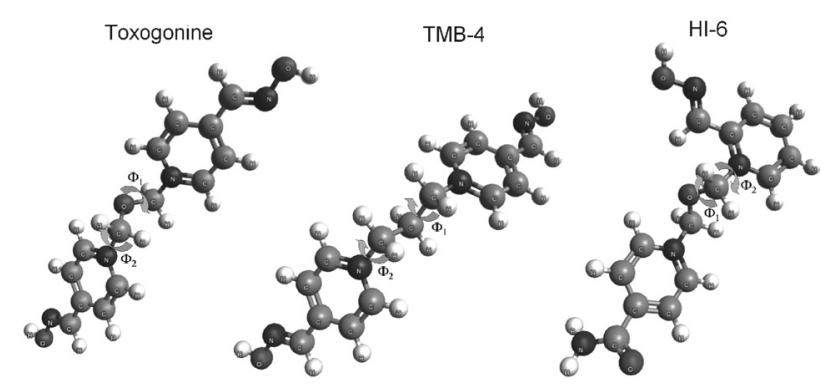

Figure 2. Oximes used in this work with dihedrals $\phi_{1}$ and $\phi_{2}$ in focus.

keywords in the input file: PRECISE CHARGE $=+2$ RM1 (or PM6) STEP=5 POINT=72 EF NOXYZ COMPFG GEOOK GRADIENTS, where CHARGE is the total charge of the system and the STEP and POINT keywords describe a coordinate as a dynamical coordinate, i.e., bond, angle and/or dihedral variation. In our case, the number of steps multiplied by the number of points gave us the total number of scanned angles $(5 \times 72=360)$. For each compound, we created two input files, one using the RM1 method and the other using the PM6 method. Each output file was parsed by a custom FORTRAN program (see supplementary information) to extract the $\mathrm{XY}$ coordinates in order to facilitate the comparison of the dihedral angle and $\Delta \mathrm{H}_{\mathrm{f}}$.

\section{Results and Discussion}

It is important to mention here that the decision to only perform the conformational analysis on the dihedrals $\Phi_{1}$ and $\Phi_{2}$ described in this work was supported by the following reasons: (i) Energetically, $\Phi_{1}$ and $\Phi_{2}$ are the dihedrals related to the highest energy points in Toxogonine, TMB-4 and HI-6 and, consequently, to the highest barriers of energy; (ii) Variations of these dihedrals intensify repulsions between two or more groups with the same charge, like aromatic rings; (iii) In order to avoid poor parameterizations and, consequently, trapping the molecule in local minima, it

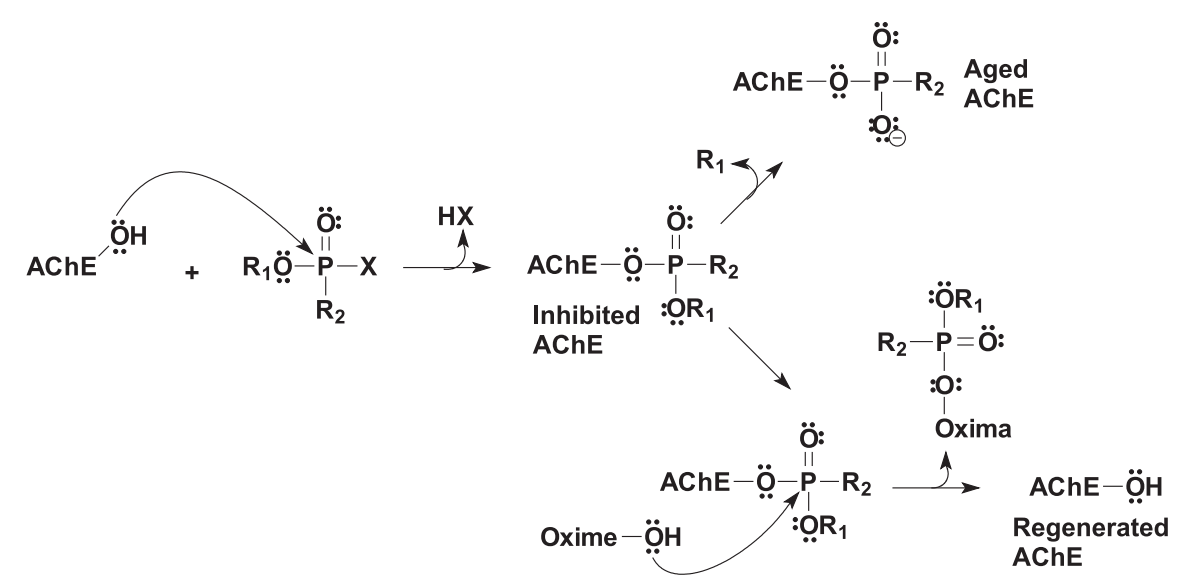

Figure 1. Inhibition, disinhibition and aging of acetylcholinesterase. $\mathrm{X}$ is the leaving group. 
is of fundamental importance to obtain information about putative minima obtained by the conformational analysis of those dihedrals; (iv) Variations in the other dihedrals in Toxogonine, TMB-4 and HI-6 do not cause enough steric effects to cause problems in further parameterizations.

In order to validate the RM1 and PM6 methods for the conformational search, we have performed the $\Phi_{2}$ dihedral variation of HI-6 from 0 to 180 degrees using DFT, ${ }^{22,23}$ with B3LYP ${ }^{24,25}$ and 6-31 G (d,p) basis sets and the RM1 and PM6 methods and compared the energy values and the energetic barriers found with each. ${ }^{26}$ In this case, despite small differences in the minimal and maximal energies, the RM1, PM6 and DFT methods presented similar profiles, as can be seen in Figure 3. The highest and lowest energy points were located, respectively, at 20 and 140 degrees with DFT, 60 and 170 degrees with RM1 and at 40 and 160 degrees with PM6.

The energetic barriers computed from each method are presented in Table 1. The difference in the barriers calculated by DFT and RM1 was $1.41 \mathrm{kcal} \mathrm{mol}^{-1}(11.38$ 9.97 in Table 1), and that between DFT and PM6 was $1.78 \mathrm{kcal} \mathrm{mol}^{-1}$ (11.38-9.60 in Table 1). These deviations are consistent with data already reported in the literature..$^{19,20}$

After searching the points of maximal energy, it was also necessary to perform a vibrational analysis of the
Table 1. Energetic barriers acquired from the methods DFT, RM1 and PM6 for the dihedral $\phi_{2}$ in HI-6

\begin{tabular}{lc}
\hline Method & Energetic barriers* \\
\hline DFT/B3LYP 6-31G*** & 11.38 \\
RM1 & 9.97 \\
PM6 & 9.60 \\
\hline
\end{tabular}

${ }^{*} \mathrm{kcal} \mathrm{mol}{ }^{-1}$.

stationary points found in the conformational analysis, in order to unequivocally characterize them as true energy maxima. ${ }^{26}$ This was done for $\Phi_{2}=140^{\circ}$ using DFT/B3LYP 6-31G(d,p), $\Phi_{2}=170^{\circ}$ using RM1 and $\Phi_{2}=160^{\circ}$ using PM6. The single negative frequency vibrations found for DFT, RM1 and PM6 were 62.94i $\mathrm{cm}^{-1}, 55.70 \mathrm{i} \mathrm{cm}^{-1}$ and $42.2 \mathrm{i} \mathrm{cm}^{-1}$, respectively. The occurrence of a single imaginary frequency indicated that a good transition state (TS) had been located, and the vibrational analysis confirmed it as a true saddle point.

For a final validation of the RM1 and PM6 methods for use in our conformational analysis, we calculated the root mean square deviations (RMSD) of the three TS geometries of HI-6 acquired by the RM1, PM6 and DFT methods. As shown in Figure 4, the three geometries presented a very good superimposition, with an RMSD of $0.269 \AA$

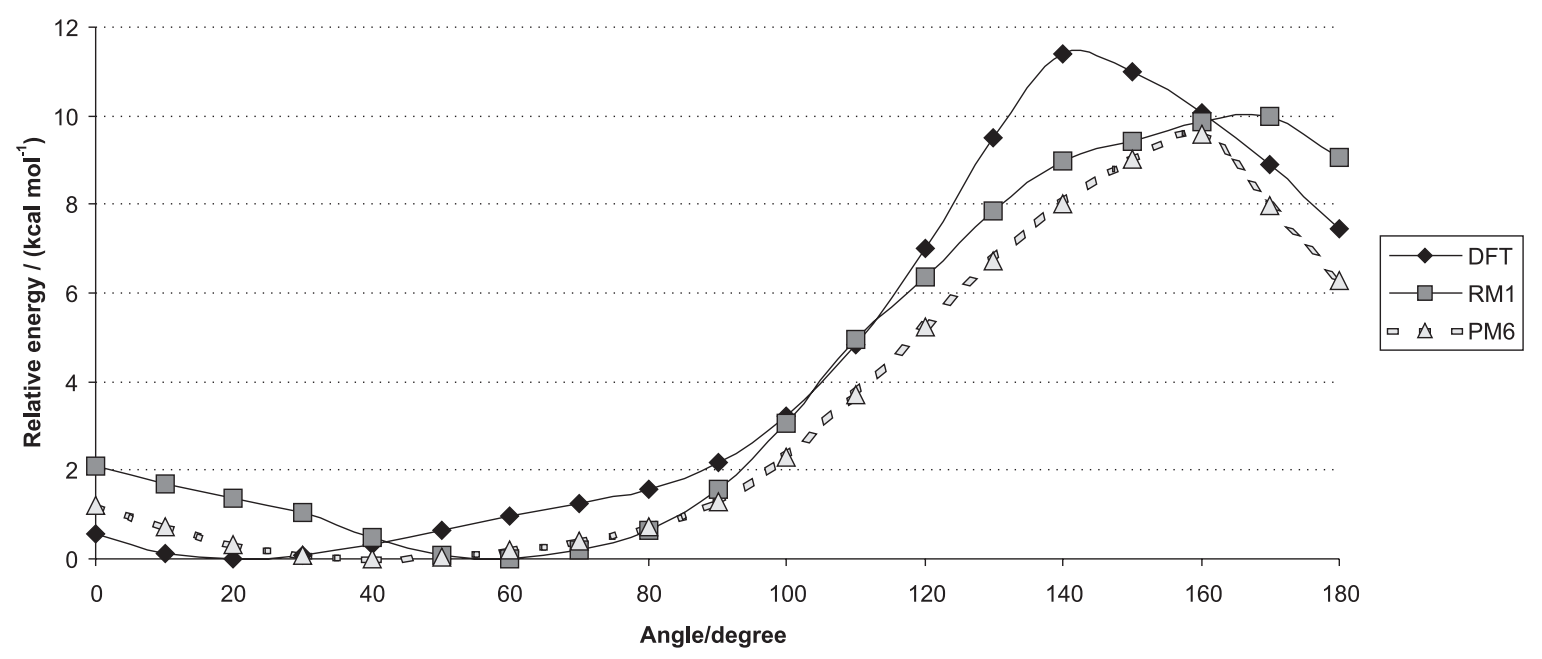

Figure 3. $\phi_{2}$ dihedral variation of HI-6, from 0 to 180 degrees, using DFT, B3LYP and the 6-31 G (d,p) basis set for the RM1 and PM6 methods.

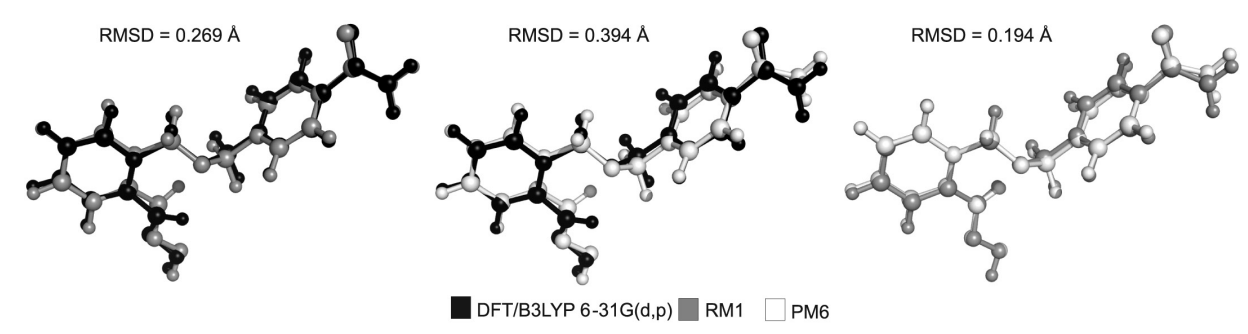

Figure 4. Superimposition of the three transition state (TS) geometries of HI-6 acquired by the RM1, PM6 and DFT methods. 
between DFT and RM1, $0.394 \AA$ \& between DFT and PM6 and $0.194 \AA$ between DFT and PM6.

After the validation of these methods, conformational analyses of Toxogonine, TMB-4 and HI-6 were performed using the RM1 and PM6 methods by varying the dihedrals $\Phi_{1}$ and $\Phi_{2}$ from 0 to 360 degrees following the procedure already described in the methodology section. As can be seen in Figure 5, our results showed that, for the dihedral $\Phi_{1}$ of Toxogonine, the lowest energy conformation was the one that presented torsion between 260 and 280 degrees. For dihedral $\Phi_{2}$ (Figure 6), two conformations were found, one between 120 and 140 degrees and the other between 300 and 320 degrees. The energetic barriers for $\Phi_{1}$ were about $14.00 \mathrm{kcal} \mathrm{mol}^{-1}$ when using the PM6 method and $16.31 \mathrm{kcal} \mathrm{mol}^{-1}$ when using the RM1 method. For the dihedral $\Phi_{2}$, the barriers determined with the PM6 and RM1 methods were 3.5 and $3.9 \mathrm{kcal} \mathrm{mol}^{-1}$, respectively, suggesting that it is easier to turn $\Phi_{2}$ than $\Phi_{1}$.

When rotating the TMB- 4 dihedral $\Phi_{1}$, even though the energy needed to transpose the barrier between the maximal and minimal energies was shown in this study to be about $5.81 \mathrm{kcal} \mathrm{mol}^{-1}$ with PM6 and $7.2 \mathrm{kcal} \mathrm{mol}^{-1}$ with RM1, intermediate conformational states were observed between the angles 60 and 100 and 200 and 300. The barriers to rotating dihedral $\Phi_{2}$ were $2.28 \mathrm{kcal} \mathrm{mol}^{-1}$ with PM6 and $2.05 \mathrm{kcal} \mathrm{mol}^{-1}$ with RM1 (Figure 6).
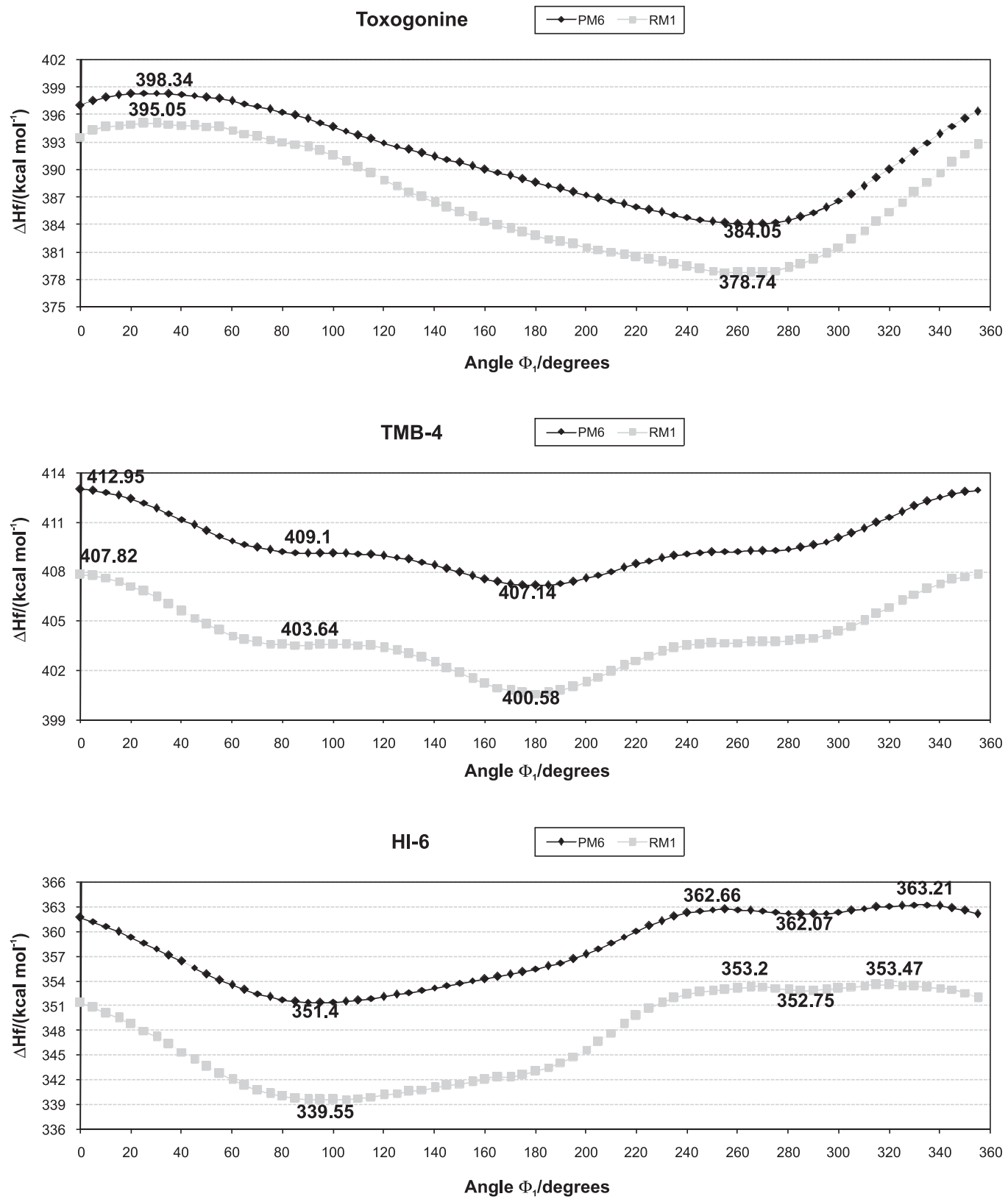

Figure 5. Plots of $\Delta \mathrm{H}_{\mathrm{f}} \times \phi_{1}$ for the oximes Toxogonine, TMB-4 and HI-6. 

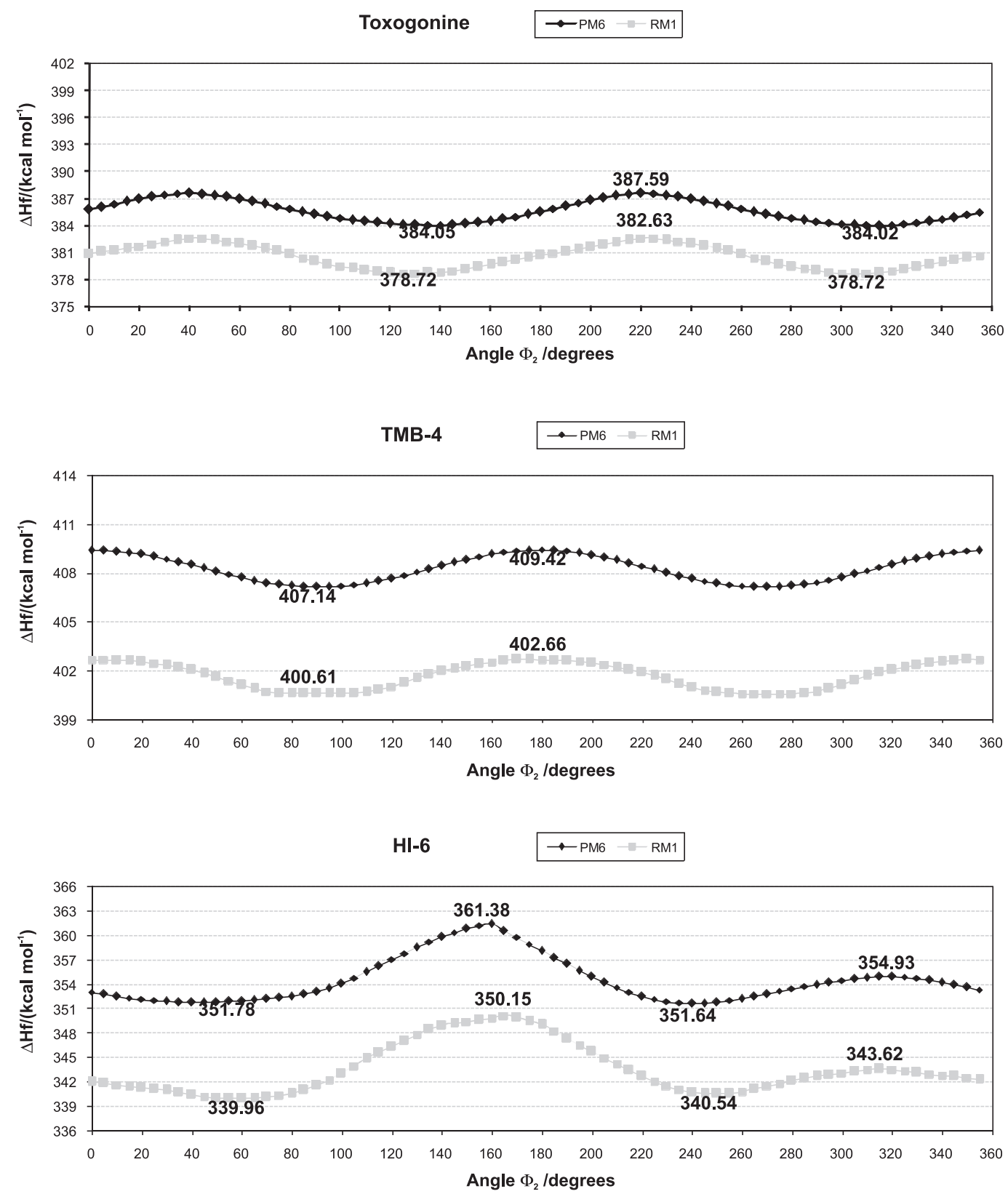

Figure 6. Plots of $\Delta \mathrm{H}_{\mathrm{f}} \times \phi_{2}$ for the oximes Toxogonine, TMB-4 and HI-6.

The results of the conformational analysis for HI-6 showed that, when varying both dihedral angles, $\Phi_{1}$ and $\Phi_{2}$, there were found, respectively, values with low (less than $3.0 \mathrm{kcal} \mathrm{mol}^{-1}$ ) and considerable (about $10.0 \mathrm{kcal} \mathrm{mol}^{-1}$ ) magnitudes, in terms of energetic barriers. As can be seen in Figure 5, the difference between the minima between 80 and 120 degrees and, for example, one of the maxima, located between 240 and 280 degrees, for the dihedral $\Phi_{1}$ was about $11.30 \mathrm{kcal} \mathrm{mol}^{-1}$ using PM6 and about $13.65 \mathrm{kcal} \mathrm{mol}^{-1}$ using RM1. This result suggests that, despite the existence of a local minimum between 280 and 320 degrees, it is difficult to cross the barrier with a magnitude between 11.00 and $14.00 \mathrm{kcal} \mathrm{mol}^{-1}$ and that the most stable conformation for $\Phi_{1}$ in $\mathrm{HI}-6$ is the one valued at $351.40 \mathrm{kcal} \mathrm{mol}^{-1}$ with PM6 and at $339.55 \mathrm{kcal} \mathrm{mol}^{-1}$ with RM1. For the analysis of the variation of the HI-6 angle $\Phi_{2}$ (Figure 6), it was shown that, for both PM6 and RM1, the major energetic barrier was about $10.00 \mathrm{kcal} \mathrm{mol}^{-1}$, suggesting that the most stable conformations are localized between the dihedral angles of 40 and 80 degrees and 240 and 260 degrees.

\section{Conclusions}

In the present work, we validated the conformational analysis of the dihedrals $\Phi_{1}$ and $\Phi_{2}$ of Toxogonine, TMB-4 and HI-6 employing the semi-empirical methods PM6 and 
RM1, by comparison with the energetic barriers obtained for the $\Phi_{2}$ dihedral angle of the oxime HI- 6 calculated using DFT, B3LYP and the 6-31 G (d,p) basis sets. The energetic profiles obtained with the semi-empirical methods were very similar to the one obtained by DFT. Additionally, the superimposition of TSs obtained with the three methods did not present significant variations.

Further application of the RM1 and PM6 methods to the conformational analysis of Toxogonine, TMB-4 and HI-6 suggested that the ideal values for the dihedral angles $\Phi_{1}$ and $\Phi_{2}$ could lead to the reduction of steric effects in future parameterizations in posterior molecular modeling studies. Using RM1 and PM6 methods for conformational analysis provides more accuracy when compared to the other semi-empirical methods like AM1 $1^{19,20}$ and PM3 $3^{19,20}$ and, at the same time, is much less time consuming when compared with DFT.

\section{Acknowledgments}

The Authors wish to thank the Brazilian agencies CNPq, FAPERJ and CAPES/PRODEFESA for financial support.

\section{Supplementary Information}

Supplementary data are available free of charge at http:// jbcs.sbq.org.br, as PDF file.

\section{References}

1. Kryger, G.; Harel, M.; Giles, K.; Toker, L.; Velan, B.; Lazar, A.; Kronman, C.; Barak, D.; Ariel, N.; Shafferman, A.; Silman, I.; Sussman, J. L. Acta Crystallogr., Sect. D: Biol. Crystallogr. 2000, 56, 1385.

2. Somani, S. M.; Solana, R. P.; Dube, S. N.; Chemical Warfare Agents, Academic Press: San Diego, 1992.

3. Black, R. M.; Harrison, J. M. In The Chemistry of Organophosphorus Compounds, Volume 4, Ter- and QuinqueValent Phosphorus Acids and Their Derivatives; Hartley, F. R. ed., John Wiley \& Sons: New York, 1996.

4. Sidell, F. R.; Takafuji, E. T.; Franz, D. R. In Textbook of Military Medicine; Office of the Surgeon General, US Army, Washington D.C., 1997, p. 129.

5. Marrs, T. C.; Maynard, R. L.; Sidell, F. R. In Chemical Warfare Agents: Toxicology and Treatment, $2^{\text {nd }}$ ed., John Wiley \& Sons: New York, 2007.

6. Wong, L.; Radic, Z.; Brüggemann, R. J. M.; Hosea, N.; Berman, H. A.; Taylor, P. Biochemistry 2000, 39, 5750.

7. Ekström, F.; Yuan-Ping, P.; Boman, M.; Artursson, E.; Akfur, C.; Börjegren, S.; Biochem. Pharmacol. 2006, 72, 597.
8. Ashani, Y.; Radic, Z.; Tsigelny, I.; Vellom, D. C.; Pickering, N. A.; Quinn, D. M.; Doctor, B. P.; Taylor, P.; J. Biol. Chem. 1995, 11,6370 .

9. Ekström, F. J.; Astot, C.; Pang, Y. P.; Clin. Pharmacol. Ther. 2007, 82, 282.

10. Worek, F.; Aurbek, N.; Koller, M.; Becker, C.; Eyer, P.; Thiermann, H. Biochem. Pharmacol. 2007, 73, 1807.

11. Castro, A. T.; Figueroa-Villar, J. D.; Int. J. Quantum Chem. 2002, 89, 135.

12. Goncalves, A. D.; Franca, T. C. C.; Wilter, A.; Figueroa-Villar, J. D.; J. Braz. Chem. Soc. 2006, 17, 968.

13. Smirnova, O. I.; Gurina, E. I.; Zhigalova, L. V.; Arestova, L. S.; Farmakologiya I Toksikologiya 1975, 38, 467.

14. Bay, E.; Federation Proceedings 1959, 18, 366.

15. Bay, E.; Krop, S.; Yates, L. F.; Proceedings of the Society for Experimental Biology and Medicine 1958, 98, 107.

16. Bartosova, L.; Kuca, K.; Jun, D.; Kunesova, G.; Int. J. Toxicol. 2005, 24, 399.

17. Hassinen, T.; Peräkylä, M.; J. Comput. Chem. 2001, 22, 1229.

18. Shih, J. H.; Chen, C. L.; Macromolecules 1995, 28, 4509.

19. Rocha, G. B.; Freire, R. O.; Simas, A. M.; Stewart, J. J.; J. Comput. Chem. 2006, 27, 1101.

20. Stewart, J. J.; J. Mol. Model. 2007, 13, 1173.

21. Frisch, M. J.; Trucks, G. W.; Schlegel, H. B.; Scuseria, G. E.; Robb, M. A.; Cheeseman, J. R.; Montgomery, J. A.; Vreven, T.; Kudin, K. N.; Burant, J. C.; Millam, J. M.; Iyengar, S. S.; Tomasi, J.; Barone, V.; Mennucci, B.; Cossi, M.; Scalmani, G.; Rega, N.; Petersson, G. A.; Nakatsuji, H.; Hada, M.; Ehara, M.; Toyota, K.; Fukuda, R.; Hasegawa, J.; Ishida, M.; Nakajima, T.; Honda, Y.; Kitao, O.; Nakai, H.; Klene, M.; Li, X.; Knox, J. E.; Hratchian, H. P.; Cross, J. B.; Bakken, V.; Adamo, C.; Jaramillo, J.; Gomperts, R.; Stratmann, R. E.; Yazyev, O.; Austin, A. J.; Cammi, R.; Pomelli, C.; Ochterski, J. W.; Ayala, P. Y.; Morokuma, K.; Voth, G. A.; Salvador, P.; Dannenberg, J. J.; Zakrzewski, V. G.; Dapprich, S.; Daniels, A. D.; Strain, M. C.; Farkas, O.; Malick, D. K.; Rabuck, A. D.; Raghavachari, K.; Foresman, J. B.; Ortiz, J. V.; Cui, Q.; Baboul, A. G.; Clifford, S.; Cioslowski, J.; Stefanov, B. B.; Liu, G.; Liashenko, A.; Piskorz, P.; Komaromi, I.; Martin, R. L.; Fox, D. J.; Keith, T.; Al-Laham, M. A.; Peng, C. Y.; Nanayakkara, A.; Challacombe, M.; Gill, P. M. W.; Johnson, B.; Chen, W.; Wong, M. W.; Gonzalez, C.; Pople, J. A.; Gaussian, Gaussian Inc.: Wallingford CT, 2004.

22. Hohenberg, P.; Kohn, W.; Phys. Rev. 1964, 136, B864.

23. Kohn, W.; Sham, L. J.; Phys. Rev. 1965, 140, 4A.

24. Becke, A. D.; J. Chem. Phys. 1993, 98, 7.

25. Lee, C.; Yang, W.; Parr, R. G.; Phys. Rev. B: Condens. Matter Mater. Phys. 1988, 37, 2.

26. We thank the referee for this suggestion.

Received: January 17, 2009 Web Release Date: October 9, 2009 


\title{
Conformational Analysis of Toxogonine, TMB-4 and HI-6 using PM6 and RM1 Methods
}

\author{
Arlan da Silva Gonçalves, ${ }^{a}$ Tanos C. C. França, ${ }^{b}$ \\ José D. Figueroa-Villar ${ }^{b}$ and Pedro G. Pascutti*,a \\ anstituto de Biofísica Carlos Chagas Filho, Universidade Federal do Rio de Janeiro, \\ 21941-902 Rio de Janeiro-RJ, Brazil
}

${ }^{b}$ Divisão de Ensino e Pesquisa, Seção de Engenharia Química, Instituto Militar de Engenharia, 22290-270 Rio de Janeiro-RJ, Brazil

cc Fortran code of program: Make Coordinate

$\mathrm{cc} * * * * * * * * * * * * * * * * * * * * * * * * * * * * * * * * * * * * * * * *$

cc Program Make Coordinate

cc Program for Linux Platform

cc Data the MOPAC program output file (*.arc), this program make an output

cc which may be imported

cc by programs as Microsoft Excel, GNUMERIC, etc

cc By: Goncalves, A.S. (2008)

cc Note1: This program only is correctly executed if we make conformational

cc search from zero to 360 degree with a step of 5 degrees.

cc

Program makecoord

character $\operatorname{arc} * 30$, nomeout*30

dimension $\mathrm{x}(1000), \mathrm{y}(1000)$

$\mathrm{a}=$ system ('clear')

$\mathrm{a}=\operatorname{system}($ 'ls -ltrh *.arc')

Print *,'Give the name of arc file'

Read *,arc

Print *, Give the name of output file'

Read *,nameout

OPEN $(1$, FILE=arc $)$

$\operatorname{OPEN}(7, \mathrm{FILE}=$ nameout $)$

do $\mathrm{m}=1,9$

$\operatorname{read}(1, *)$

enddo

$1=1$

do $\mathrm{n}=1,9$

$\operatorname{read}\left(1,{ }^{\prime}(8 f 7.2)^{\prime}\right) \times(1), x(1+1), x(1+2), x(1+3), x(1+4), x(1+5)$

$\&, \mathrm{x}(1+6), \mathrm{x}(1+7)$

$\operatorname{read}\left(1,{ }^{\prime}(8 f 7.2)^{\prime}\right) \mathrm{y}(1), \mathrm{y}(1+1), \mathrm{y}(1+2), \mathrm{y}(1+3), \mathrm{y}(1+4), \mathrm{y}(1+5)$

$\&, y(1+6), y(1+7)$

$\operatorname{read}(1, *)$

$1=1+8$

enddo

do $\mathrm{n}=1,72$

write(7,'(f7.2,2x,f7.2)') x(n),y(n)

enddo

end

*e-mail: pascutti@biof.ufrj.br 